\title{
Characterising changes in the numerical competence and confidence of students between MPharm I and MPharm II
}

Authors: Sion Coulman, Farah Arikat and Dai John. Cardiff School of Pharmacy and Pharmaceutical Sciences, Cardiff University

Background: Diagnostic numeracy tools are valuable in testing inherent numeracy skills of incoming university students. ${ }^{1}$ The study aims were to use a diagnostic numeracy tool to establish if the numerical competence and confidence of MPharm students at one UK school of pharmacy improved after one year in higher education and to determine the factors which govern numeracy skills.

Method: In October 2011, MPharm I students sat a contextualised diagnostic numeracy test and one year later (on entering MPharm II) sat exactly the same test. Students were not informed in advance of the test. Statistical analyses were conducted in SPSS on the data of 140 students. Ethics approval was obtained.

Results: Score $(p<0.001)$ and confidence $(p<0.001)$ significantly increased between Year 1 (score= 20.3/25 \pm 4.33 ; confidence $=18.2 / 25 \pm 6.17$ ) and Year 2 (score= 22.2/25 \pm 3.36 ; confidence $=21.5 / 25 \pm 4.61$ ). Students principally educated in Malaysia had higher scores and greater confidence. This was also true for students whose highest mathematics qualification was A level compared to those without A level. Scores and confidence did not differ significantly between males and females. The most frequent incorrectly/least confidently answered questions involved unit conversions and multi-step calculations.

Discussion: Feedback after the first year test and MPharm I pharmaceutical calculations teaching may have contributed to the improvement in numeracy skills. Different countries' teaching methods ${ }^{2}$ can impact on numeracy skills and MPharm students with A level mathematics have stronger numeracy skills ${ }^{3}$ than those without and so careful consideration of the MPharm entry requirements may be useful. The weakness in the numeracy domains identified should ideally be tackled prior to university entry. A limitation of the study is that students from only one university were involved. Future research could see the involvement of other schools of pharmacy.

\section{References}

1. Sharif S, Gifford LA, Morris GA, Barber J. Diagnostic testing of first year pharmacy students: a tool for targeted student support. Pharmacy Education. 2007;7:215-221. 2. Hitch G, West D, Jee R, Foulsham R, Pearce B. A novel visually-displayed test for assessing numerical skills in pharmacy undergraduates. Pharmacy Education. 2010;10:144-148.

3. Lee S, Browne R, Dudzic S, Stripp C. Understanding the UK Mathematics Curriculum Pre-Higher Education: a guide for Academic Members of Staff. Leicestershire: The Higher Education Engineering Subject Centre; 2010. 